\title{
PROCESSO DECISÓRIO EM SISTEMAS DE INFORMAÇÃO: UM LEVANTAMENTO BIBLIOGRÁFICO DA PRODUÇÃO CIENTÍFICA NACIONAL
}

\author{
DECISION MAKING IN INFORMATION SYSTEMS: A BIBLIOGRAPHIC \\ SURVEY OF THE NATIONAL SCIENTIFIC PRODUCTION
}

\author{
Monize Sâmara Visentini ${ }^{1}$, Rodrigo Prante Dill ${ }^{2}$ e Dionéia Dalcin ${ }^{3}$
}

Recebido em: 15/04/2016 Aprovado em: 06/06/2016

\section{RESUMO}

Este estudo objetiva analisar comparativamente a produção científica nacional sobre processo decisório em Sistemas de Informação, por meio de artigos publicados nos anais do Encontro da Associação Nacional de Pós-Graduação e Pesquisa em Administração (EnANPAD) e do Encontro de Administração da Informação (EnADI), entre 1999 e 2014. Investigaram-se 124 trabalhos, com foco na relação entre estratégia metodológica, período de publicação e coautoria. Relativo às estratégias, classificaram-se os trabalhos em quantitativos, qualitativos ou multimétodo. Percebeu-se predominância de estudos quantitativos no EnANPAD e de estudos qualitativos no EnADI. Quanto às estratégias quantitativas, constatou-se a predominância de aplicação de uma única estratégia por artigo, sendo a estatística descritiva, a análise fatorial exploratória e a análise de confiabilidade as mais presentes. No que concerne às estratégias qualitativas, consideradas em termos tanto de técnicas de coleta de dados quanto de métodos de pesquisa, constatou-se a predominância de estudo de caso, ensaio teórico e análise de conteúdo. Nos estudos multimétodo, observou-se a utilização conjunta do estudo de caso e da estatística descritiva ou de técnicas de pesquisa operacional. Verificou-se, ainda, uma tendência de artigos publicados em coautoria, indicando que os pesquisadores percebem a importância do estabelecimento de parcerias acadêmicas para a evolução do seu campo de estudo.

Palavras-chaves: Decisão; Sistemas de informação; Levantamento bibliográfico

\begin{abstract}
This paper aims to analyze comparatively the national scientific literature on decision-making in Information Systems, through articles published in the proceedings of the Conference of National Association of Postgraduation and Research in Administration (EnANPAD) and the Information Management Meeting (EnADI) from 1999 to 2014. We investigated 124 papers analyzing the relationship between methodological strategies, publishing period and co-authoring. Concerning research strategies, papers were ranked in quantitative, qualitative or multimethod. We noted the predominance of quantitative studies in EnANPAD and qualitative studies in EnADI. Regarding the quantitative strategies, there was a predominance of applying a single strategy per paper, with descriptive statistics, exploratory factor anal$y$ sis and reliability analysis the most present. With regard to qualitative strategies, considered in terms of data collection techniques and research methods, there was predominance of case studies, theoretical essay and content analysis. In multimethod studies we observed the joint use of case study combined with descriptive statistics or operational research techniques. We also verified a tendency of the publication in co-authored, indicating that researchers realize the importance of establishment of academic partnerships for the development of your study field.
\end{abstract}

Keywords: Decision; Information system; Bibliographic study.

${ }^{1}$ Doutora em Administração pela Universidade Federal do Rio Grande do Sul (UFGRS), Brasil. Atua como docente na Universidade Federal da Fronteira Sul (UFFS). E-mail: monize.visentini@uffs.edu.br.

${ }^{2}$ Mestre em Administração pela Universidade Federal de Santa Catarina (UFSC), Brasil. Atua como docente na Universidade Federal da Fronteira Su (UFFS).E-mail: rodrigo.dill@uffs.edu.br.

${ }^{3}$ Doutora em Agronegócios pela Universidade Federal do Rio Grande do Sul (UFGRS), Brasil. Atua como docente na Universidade Federal da Fronteira Sul (UFFS). E-mail: dioneia.dalcin@uffs.edu.br. 


\section{Introdução}

No Brasil, a área da Administração enquanto ciência se expandiu significativamente nas últimas décadas. Vide, por exemplo, o Encontro da Associação Nacional de Pós-Graduação e Pesquisa em Administração (EnANPAD), no qual, em 1997, em sua XXI edição, foram apresentados 244 trabalhos. Na edição realizada em 2014, 2.350 trabalhos foram submetidos, dos quais 880 foram aprovados em onze diferentes áreas temáticas. Essa expansão é corroborada por Cirani, Da Silva e Campanário (2012), que discutem a evolução do ensino da pós-graduação estrito senso em Administração no Brasil. Segundo o estudo, em 1998, existiam oito cursos de doutorado e dezoito cursos de mestrado acadêmico em Administração, ao passo que, no ano de 2011, existiam 29 cursos de doutorado e 57 de mestrado acadêmico. Além disso, nos últimos vinte anos, inúmeras revistas científicas dedicadas à Administração se consolidaram ou foram editadas.

Nesse processo, novas áreas, além daquelas consideradas tradicionais (como Marketing, Finanças, Produção e Recursos Humanos), conquistaram espaço, possivelmente por demandas das organizações, pelo envolvimento de pesquisadores ou, até mesmo, pela curiosidade científica. Atualmente, algumas dessas novas áreas, já não tão novas assim, ultrapassaram campos tradicionais no número de publicações, pesquisadores e praticantes. A área de Administração da Informação (ADI), por exemplo, no EnANPAD de 2014, recebeu para avaliação 58 trabalhos, superando disciplinas consolidadas, como Finanças, Contabilidade e Logística. Ressalta-se, ainda, que bianualmente se realiza, desde o ano de 2007, um evento denominado Encontro Nacional de Administração da Informação (EnADI), dedicado exclusivamente à ADI.

À medida que determinada área de conhecimento se desenvolve, sur- ge a tarefa de mensurar, caracterizar e avaliar a ciência por ela produzida, ou seja, de avaliar os resultados da atividade intelectual publicizada por seus pesquisadores. A produção acadêmica da Administração no Brasil começou a ser objeto de estudo na década de 1990, a partir dos trabalhos de Siqueira e Machado-da-Silva (1988) e Cunha e Amboni (1990), que analisaram a produção científica brasileira na área de organizações. Bertero, Caldas e Wood Júnior (1998, 1999), Wood Júnior e Paula (2002) e Fleury (2003), por sua vez, analisaram o campo da Administração de forma ampla. De acordo com Machado-da-Silva, Cunha e Amboni (1990), por meio da investigação da produção acadêmica, pode-se conhecer o estado de transformação de um campo de conhecimento, suas tendências teóricas e metodológicas, as orientações básicas que norteiam os estudiosos do assunto, entre outros aspectos relevantes.

O processo decisório em ADI é um tema específico (Processo Decisório e Sistemas de Apoio à Decisão) no EnANPAD e no EnADI, envolvendo diversos pesquisadores e instituições. De acordo com um estudo realizado por Freitas, Becker e Marcolin (2014), que descreve o panorama da pesquisa acadêmica em Sistema de Informação (SI) no Brasil, no período compreendido entre 1994 e 2013, em um contexto de 1.105 trabalhos analisados, o termo "decisão" foi identificado como um dos conceitos-chave mais frequentes. Ainda, ao analisar o período compreendido entre 2003 e 2013, diagnosticou-se o termo "tomada de decisão", juntamente com outros seis temas, presente em $80 \%$ a $90 \%$ dos artigos.

Devido ao desenvolvimento, no Brasil, da temática de processo decisório em $\mathrm{SI}^{4}$ e à ausência de estudos bibliométricos nas bases de dados nacionais, delineou-se como objetivo deste estudo analisar comparativa e evolu-

\footnotetext{
${ }^{4}$ Em se tratando de área temática ou campo de investigação, consideraram-se as áreas de Sistema de Informação (SI) e Administração da Informação (ADI) como sinônimas.
} 
cionariamente a produção científica nacional sobre processo decisório em SI, nos eventos da Associação Nacional de Pós-Graduação e Pesquisa em Administração (ANPAD): EnANPAD e EnADI. Para tanto, propõe-se discutir as estratégias metodológicas utilizadas (qualitativas, quantitativas e multimétodo); a evolução quantitativa dos artigos publicados por evento e estratégia; o número de estratégias utilizadas por artigo e sua evolução por evento e estratégia; e a evolução e a relação entre o número de artigos publicados e o número de autores.

A realização deste trabalho se justifica pela intenção pioneira de investigar as características da produção científica da temática do processo decisório no campo do SI, tendo em vista a escassez de pesquisas de cunho bibliométrico que abranjam esse campo do conhecimento e a importância deste para o suporte da gestão organizacional. Acredita-se que este estudo possibilitará um panorama avaliativo, além de reflexões em torno dessa emergente temática de investigação.

\section{O processo decisório e os Sistemas de Informação}

O processo decisório é frequente para os gestores e, muitas vezes, implica um comprometimento em longo prazo que dificilmente é revertido. Como se trata de um tema bastante abrangente (LÖBLER, 2005), sua conceptualização e caracterização é importante. Segundo Becker et al. (1997, p. 11), "é por meio de suas decisões que os administradores procuram conduzir seu negócio a uma determinada situação".

Trata-se de temática central para diversos pesquisadores e relevante para as organizações. No meio acadêmico, parece não haver consenso entre as perspectivas adotadas nos estudos existentes. Contudo, podem-se apontar as visões racionalista, política e garbage can, que se originam de pressupostos diferentes, mas buscam compreender o comportamento do tomador de decisões e dar suporte para o aprimoramento da ciência administrativa (GIBCUS; VERMEULEN; RADULOVA, 2008).

A visão racionalista está associada aos trabalhos dos economistas da primeira metade do século XX. Nestes trabalhos, o decisor é descrito como plenamente informado e totalmente racional. Um exemplo desse entendimento pode ser constatado na obra de Nash (1950) sobre o problema de barganha (RAMOS; TAKAHASHI; ROGLIO, 2015). Mais tarde, a corrente racionalista é influenciada por Simon (1945), ao induzir à noção de racionalidade limitada. Nesta visão, é recusado o modelo de que o tomador de decisões pode obter a solução ótima, pois este é, necessariamente, limitado pela possibilidade de reunir todas as informações relacionadas ao tema para que possa decidir. Outra linha de investigação, abordada nos estudos de Tvesrky e Kahneman (1973, 1974), consistiu na tentativa de identificar os erros sistemáticos de pensamento que afastam o homem do ideal preconizado pelos economistas.

A visão política, impulsionada pela proliferação de estudos na área da ciência política na década de 1950 , possui caráter normativo, valorativo e relacional da tomada de decisão. Seu pressuposto básico é de que a decisão passa necessariamente pela negociação entre os envolvidos. Em outras palavras, a intenção é investigar as formas como os participantes do processo podem usar o poder ou a influência para alterar o curso e os resultados do processo (CHILD; ELBANNA; RODRIGUES, 2010).

Por fim, a visão garbage can, defendida por Cohen, March e Olsen (1972), opõe-se às visões racionalista e política, propondo a inclusão de elementos até então ignorados. Esse modelo teórico foi desenhado a partir de uma simulação de computador em que decisões, problemas e decisores se encontram em função de fluxos de energia necessários 
para a resolução dos problemas. Nessa descrição do processo decisório, os objetivos são múltiplos e contraditórios, a tecnologia é ambígua, e as decisões são fruto de encontros fortuitos entre decisores, problemas e soluções (GIBSON, 2012). Tal configuração tem sustentado investigações empíricas em cenários em que os modelos racionais parecem não descrever bem a realidade.

Para o suporte à tomada de decisão nas organizações, são adotados os Sistemas de Informações Gerenciais (SIG), que possibilitam, além de informação pontual, respostas às operações diárias, agregando, assim, valores aos processos da organização (HÉKIS et al., 2013). Os SIG são definidos, de forma geral, como um conjunto de elementos, pessoas, hardwares, softwares, redes de comunicações e recursos de dados, associados e interagentes, que geram informações como base para o processo decisório (CAUTELA; POLLONI, 1991; SIQUEIRA, 2005; CASSARRO, 1998; O'BRIEN, 2004; LAUDON; LAUDON, 2004). Além de darem suporte à tomada de decisões, à coordenação e ao controle, esses sistemas também auxiliam os gerentes e trabalhadores a analisar problemas, visualizar assuntos complexos e criar novos produtos (LAUDON; LAUDON, 2004).

Já as informações como um todo fornecem apoio à tomada de decisão organizacional, mas de forma mais específica. Dentre os tipos de SI existentes (O'BRIEN, 2004), o sistema de apoio à decisão (SAD ou DSS) é o que contribui para o processo de tomada decisão. Os SADs tratam de assuntos específicos, estatísticas, projeções e comparações de dados referentes ao desempenho da empresa, para apoiar a tomada de decisões semiestruturadas e não estruturadas por parte dos gerentes (O'BRIEN, 2004; POLLONI, 2000), corroborando para a obtenção de vantagens competitivas no mercado em que atuam e auxiliando em decisões simples e/ou complexas.

\section{Método}

Baseando-se no objetivo ora proposto, este artigo pode ser classificado como descritivo, tendo em vista que "procura descobrir, com a precisão possível, a frequência com que um fenômeno ocorre, sua relação e conexão com outros, sua natureza e características" (CERVO; BERVIAN, 2002, p. 66). A população deste estudo compreende os artigos publicados no EnADI, nas edições de 2007, 2009, 2011 e 2013; e aqueles publicados na área temática de ADI do EnANPAD, no período de 1999 a2014. Diante da definição da população da pesquisa, partiu-se para a seleção da amostra do estudo, que foi realizada por meio de busca nos CD-ROMs dos anais dos eventos, bem como por meio da ferramenta de busca do site da ANPAD. As palavras de filtro utilizadas para a seleção da amostra foram "decisão" e "decisório", contidas no título e/ou resumo do artigo. Conforme destacado em Löbler, Visentini e Ferreira (2011), a busca no título justifica-se na medida em que este deve traduzir fielmente o conteúdo central do artigo, ser conciso e informativo. Além disso, os títulos são utilizados com frequência em sistemas de recuperação de informações. A busca nos resumos dos trabalhos foi incluída, pois algumas das palavras específicas podem não estar presentes no título, ampliando, assim, a possibilidade de artigos selecionados para a análise. Ao total, foram selecionados 194 artigos, submetidos ao processo de leitura dos resumos para identificação da adequação ao propósito deste estudo, resultando em uma amostra final de 124 artigos. O detalhamento desta seleção pode ser visualizado na Tabela 1, exposta a seguir. 
Tabela 1 - Detalhamento dos artigos filtrados

\begin{tabular}{ccccccc}
\hline & \multicolumn{2}{c}{ Não avaliados } & \multicolumn{2}{c}{ Avaliados } & \multicolumn{2}{c}{ Total } \\
& $\mathrm{N}$ & $\%$ & $\mathrm{~N}$ & $\%$ & $\mathrm{~N}$ & $\%$ \\
\hline EnANPAD & 32 & 16,5 & 86 & 44,3 & 118 & 60,8 \\
EnADI & 38 & 19,6 & 38 & 19,6 & 76 & 39,2 \\
\hline Total & 70 & 36,1 & 124 & 63,9 & 194 & 100,0 \\
\hline
\end{tabular}

Fonte: elaborada pelos autores.

Dos 124 artigos selecionados para análise, 86 são do EnANPAD, e 38 são do EnADI. Este resultado era esperado, tendo em vista que o número de edições do EnANPAD avaliadas é muito superior ao de edições do outro evento. Para atingir o objetivo proposto, a análise dos resultados centrou-se na discussão referente à estratégia metodológica utilizada nos artigos, isto é, na classificação dos estudos em quantitativos, qualitativos ou multimétodo (quando ambas as estratégias são utilizadas). De modo complementar, discutiram-se as características da publicação sobre processo decisório em ADI, conside- rando a relação entre autoria, estratégia metodológica e período de publicação.

No que se refere à discussão das estratégias quantitativas dos artigos analisados, utilizou-se como base os trabalhos de Palmer, Sesé e Montaño (2005) e Sesé e Palmer (2012). Entretanto, como esses trabalhos focaram, exclusivamente, técnicas estatísticas predominantes nas áreas de Turismo e Saúde, respectivamente, foi necessária a adaptação dos modelos de análise propostos para o campo da Administração, tendo em vista as suas particularidades. As estratégias quantitativas analisadas podem ser verificadas no Quadro 1.

\begin{tabular}{|c|l|}
\hline $\begin{array}{c}\text { Estratégias } \\
\text { quantitativas }\end{array}$ & \multicolumn{1}{c|}{ Definição } \\
\hline $\begin{array}{c}\text { Estatística des- } \\
\text { critiva }\end{array}$ & $\begin{array}{l}\text { Organiza e descreve os dados de três maneiras: por meio de tabelas, grá- } \\
\text { ficos e medidas descritivas; contagens de frequência; e medidas de ten- } \\
\text { dência central (HAIR Jr. } \text { et al., 2005b). }\end{array}$ \\
\hline $\begin{array}{c}\text { Análise fatorial } \\
\text { exploratória }\end{array}$ & $\begin{array}{l}\text { Resume um grande número de variáveis originais em um número peque- } \\
\text { no de vários entendimentos de dados (LATIF, 1994). }\end{array}$ \\
\hline $\begin{array}{c}\text { Análise de con- } \\
\text { fiabilidade }\end{array}$ & $\begin{array}{l}\text { Utilizada para medir a confiabilidade de um instrumento de validação, } \\
\text { como, por exemplo, o Alfa de Cronbach, que avalia a magnitude em } \\
\text { que os itens de um instrumento estão correlacionados (CORTINA, 1993; } \\
\text { RICHARSON, 1989). }\end{array}$ \\
\hline Teste $t$ & $\begin{array}{l}\text { Teste paramétrico em que duas amostras de dados são coletadas e a mé- } \\
\text { dia das amostras é calculada. Existem dois tipos de teste } t \text { : o teste } t \text { de- } \\
\text { pendente e o teste } t \text { independente (FIELD, 2009). }\end{array}$ \\
\hline $\begin{array}{c}\text { Análise de } \\
\text { correlação }\end{array}$ & $\begin{array}{l}\text { Técnica associativa que ajuda a determinar se há uma relação coerente e } \\
\text { sistemática entre duas ou mais variáveis. O coeficiente de correlação de } \\
\text { Pearson é o mais comum (HAIR Jr. et al. 2005a). }\end{array}$ \\
\hline $\begin{array}{c}\text { Modelagem de } \\
\text { equações estru- } \\
\text { turais }\end{array}$ & $\begin{array}{l}\text { Avalia, simultaneamente, relações entre múltiplos construtos, com base } \\
\text { em métodos estatísticos, correlações e análise de regressão, incluindo } \\
\text { variáveis latentes dependentes e independentes, e avalia erros de medi- } \\
\text { das nas variáveis, possibilitando, assim, a análise de múltiplos parâme- } \\
\text { tros, suas causas, sua simultaneidade e sua interdependência (KLEM, } \\
\text { 2006; HAIR Jr. et al., 2005a). }\end{array}$ \\
\hline $\begin{array}{c}\text { Regressão } \\
\text { linear múltipla }\end{array}$ & $\begin{array}{l}\text { Ferramenta que analisa a relação entre duas ou mais variáveis, de modo } \\
\text { que uma variável possa ser explicada (variável dependente) pelas outras } \\
\text { variáveis (independentes) (PAULA, 2004; HAIR Jr. } \text { et al., 2005b). }\end{array}$ \\
\hline
\end{tabular}

(Continua) 
(Continuação)

\begin{tabular}{|c|l|}
\hline $\begin{array}{c}\text { Estatística não } \\
\text { paramétrica }\end{array}$ & $\begin{array}{l}\text { Os testes não paramétricos são aplicados a uma diversidade de situações, } \\
\text { porque não exigem a normalidade dos dados. Como exemplo, podem- } \\
\text { se citar: qui-quadrado, Kruskall-Wallis e modelos lineares generalizados } \\
\text { (FIELD, 2009; HAIR Jr. et al., 2005a). }\end{array}$ \\
\hline $\begin{array}{c}\text { Técnicas de } \\
\text { pesquisa opera- } \\
\text { cional }\end{array}$ & $\begin{array}{l}\text { Método para análise de decisões complexas concernentes às operações } \\
\text { sob o controle gerencial, que envolve a otimização combinatória, a pro- } \\
\text { gramação linear (GOLDBARG; LUNA, 2005) e os métodos multicrité- } \\
\text { rio de apoio à decisão. }\end{array}$ \\
\hline $\begin{array}{c}\text { Lógicas } \\
\text { não clássicas }\end{array}$ & $\begin{array}{l}\text { A Lógica pode ser dividida em lógica dedutiva e lógica indutiva. Cada uma } \\
\text { delas, por sua vez, divide-se em clássica e não clássica As não clássicas sub- } \\
\text { dividem-se em complementares (epistêmicas, modais e outras) e heterodo- } \\
\text { xas (polivalente, difusa, paraconsistente e outras) (ABE et al., 2011). }\end{array}$ \\
\hline ANOVA & $\begin{array}{l}\text { Técnica paramétrica univariada, sendo designada especificamente para } \\
\text { testar se duas ou mais populações têm a mesma média (WEBSTER, 2006). }\end{array}$ \\
\hline Regressão & $\begin{array}{l}\text { Descreve as relações entre a variável resposta (Y) e a variável explicati- } \\
\text { va (X), sendo a variável resposta dicotômica e baseada na transformação } \\
\text { logística }\end{array}$ \\
\hline
\end{tabular}

Quadro 1- Estratégias quantitativas avaliadas

Fonte: elaborado pelos autores.

Complementarmente às estratégias quantitativas, avaliaram-se as estratégias qualitativas ${ }^{5}$ dos estudos selecionados. Para nortear a análise dessas técnicas, utilizou-se como base as técnicas mencionadas por Mazzon e Hernandez (2013), em um trabalho no campo da Administração. Ressalta-se que Mazzon e Hernandez (2013) consideram, para a análise de dados qualitativos, tanto técnicas de análise de dados qualitativos (análise de conteúdo, análise documental e análise do discurso) quanto métodos de pesquisa qualitativa (estudo de caso e entrevista em profundidade), embasando a construção do Quadro 2, na qual são definidas as estratégias qualitativas adotadas para análise neste estudo.

\begin{tabular}{|c|l|}
\hline $\begin{array}{c}\text { Estratégia } \\
\text { qualitativa }\end{array}$ & \multicolumn{1}{c|}{ Definição } \\
\hline Estudo de caso & $\begin{array}{l}\text { Pode ser único ou múltiplo e compreende uma investigação empírica, coma a } \\
\text { lógica do planejamento, da coleta e da análise dos dados (YIN, 2005). }\end{array}$ \\
\hline Ensaio teórico & $\begin{array}{l}\text { Discussão formal e concludente que busca o esgotamento de uma } \\
\text { temática, com aporte em documentação e bibliografias (RICHARD- } \\
\text { SON, 2007; BARDIN, 1977). }\end{array}$ \\
\hline $\begin{array}{c}\text { Análise de } \\
\text { conteúdo }\end{array}$ & $\begin{array}{l}\text { Metodologia usada para descrever, compreender e interpretar uma } \\
\text { comunicação verbal ou não verbal, tendo como base documentos, } \\
\text { filmes, cartas e livros (BARDIN, 1977; RICHARDSON, 2007). }\end{array}$ \\
\hline $\begin{array}{c}\text { Entrevista em } \\
\text { profundidade }\end{array}$ & $\begin{array}{l}\text { São entrevistas não estruturadas, em que o entrevistador qualificado } \\
\text { faz uma pergunta ampla e o entrevistado relata de forma específica } \\
\text { sobre o tema (MATTOS, 2010; RICHARDSON, 2007). }\end{array}$ \\
\hline Análise documental & $\begin{array}{l}\text { Consiste em identificar, verificar e apreciar os documentos (registros es- } \\
\text { critos) com finalidade específica (OLIVEIRA, 2007; MOREIRA, 2005). }\end{array}$ \\
\hline Análise do discurso & $\begin{array}{l}\text { O estudo da língua sob a perspectiva discursiva, contemplando o } \\
\text { contexto histórico-social, os interlocutores, o lugar de onde falam e a } \\
\text { imagem que fazem de si, do outro e do assunto de que estão tratando } \\
\text { (ORLANDI, 1999; RICHARDSON, 2007). }\end{array}$ \\
\hline
\end{tabular}

Quadro 2 - Estratégias quantitativas avaliadas

Fonte: elaborado pelos autores.

${ }^{5}$ Para os estudos qualitativos, seguindo Mazzon e Hernandez (2013), 
No que se refere à análise acerca das características das publicações selecionadas, utilizou-se como base a estrutura de discussão apresentada em Lunardi, Rios e Maçada (2005), Rossoni e Hocayen-da-Silva (2007) e Espartel et al. (2013). Na visão de Osca-Lluch (2010), esse tipo de análise proporciona maior familiarização dos pesquisadores com a sua área científica, pois estes podem conhecer melhor os caminhos da atividade investigativa que vêm sendo empregados.

Para a análise dos resultados, utilizou-se o suporte da ferramenta Microsoft Excel ${ }^{\circledR}$, versão 2010. Por fim, para facilitar a discussão dos resultados, os artigos do EnANPAD foram agrupadas em biênios, totalizando oito biênios de análise; já os artigos do EnADI foram analisados conforme o ano de realização do evento.

\section{Apresentação e discussão dos resul- tados}

A análise deste trabalho compreendeu 124 artigos extraídos dos anais dos últimos dezesseis anos do EnANPAD e das quatro edições do EnADI. A distribuição desses artigos por ano, evento e estratégia metodológica é descrita na Tabela 2.

Tabela 2 - Artigos publicados por ano e estratégia metodológica

\begin{tabular}{ccccccccc}
\hline & \multicolumn{2}{c}{ Quantitativo } & \multicolumn{2}{c}{ Qualitativo } & \multicolumn{2}{c}{ Multimétodo } & \multicolumn{2}{c}{ Total } \\
& $\mathrm{N}$ & $\%$ & $\mathrm{n}$ & $\mathbf{0}$ & $\mathrm{n}$ & $\%$ & $\mathrm{~N}$ & $\%$ \\
\hline $1999-00$ & 3 & 3,5 & 1 & 1,2 & 2 & 2,3 & 6 & 7,0 \\
$2001-02$ & 5 & 5,8 & 0 & 0,0 & 0 & 0,0 & 5 & 5,8 \\
$2003-04$ & 2 & 2,3 & 2 & 2,3 & 0 & 0,0 & 4 & 4,7 \\
$2005-06$ & 7 & 8,1 & 5 & 5,8 & 1 & 1,2 & 13 & 15,1 \\
$2007-08$ & 4 & 4,7 & 5 & 5,8 & 3 & 3,5 & 12 & 14,0 \\
$2009-10$ & 6 & 7,0 & 5 & 5,8 & 7 & 8,1 & 18 & 20,9 \\
$2011-12$ & 6 & 7,0 & 3 & 3,5 & 4 & 4,7 & 13 & 15,1 \\
$2013-14$ & 7 & 8,1 & 8 & 9,3 & 0 & 0,0 & 15 & 17,4 \\
\hline Total & 40 & 46,5 & 29 & 33,7 & 17 & 19,8 & 86 & 100,0 \\
\hline & & & & EnADI & & & & \\
2007 & 4 & 10,5 & 4 & 10,5 & 4 & 10,5 & 12 & 31,6 \\
2009 & 2 & 5,3 & 4 & 10,5 & 1 & 2,6 & 7 & 18,5 \\
2011 & 2 & 5,3 & 5 & 13,2 & 5 & 13,2 & 12 & 31,6 \\
2013 & 4 & 10,5 & 2 & 5,3 & 1 & 2,6 & 7 & 18,4 \\
\hline Total & 12 & 31,6 & 15 & 39,5 & 11 & 28,9 & 38 & 100,0 \\
\hline Total geral & $\mathbf{5 2}$ & & $\mathbf{4 4}$ & & $\mathbf{2 8}$ & & $\mathbf{1 2 4}$ & \\
\hline
\end{tabular}

Fonte: elaborada pelos autores.

Dentre os artigos publicados no EnANPAD, 46,5\% adotaram a estratégia quantitativa; $33,7 \%$, a estratégia qualitativa; e $19,8 \%$, ambas as estratégias. Tal resultado vai de encontro do referenciado por Rossoni e Hocayenda-Silva (2007), que, ao analisarem a produção científica em ADI dos artigos publicados nos anais do EnANPAD, entre os anos de 2001 e 2006, encontraram 52\% de estudos qualitativos, $44 \%$ de quantitativos e $4 \%$ de multimé- todo. A título de comparação com esse trabalho, ao analisar o mesmo período (2001-2006), os resultados encontrados nesta pesquisa para os estudos investigativos de processo decisório na área de ADI indicam que esta, ao explorar em maior proporção técnicas quantitativas de análise, busca a sua consolidação por meio do uso de técnicas estatísticas, que podem auxiliar a descobrir relações complexas entre as variáveis em estudo (SESÉ; PALMER, 2012). 
Esse padrão não é encontrado quando se analisam os trabalhos do EnADI, tendo em vista que nesse evento há uma maior proporção de estratégias qualitativas $(39,5 \%)$, em detrimento de estratégias quantitativas $(31,6 \%)$ e multimétodo (28,9\%). Analisando, especificamente, os artigos quantitativos desse evento, percebe-se certa sazonalidade na aplicação dessas estratégias. Por ser o EnADI um evento específico da área de SI, pode ser que haja certa tendência de suas publicações buscarem discorrer mais detalhadamente sobre a complexidade do problema investigado, por meio da análise aprofundada da interação de certas variáveis, característica dos estudos qualitativos. Nesse sentido, Morgan e Smirich (1980) destacam que as pesquisas qualitativas visam aprofundar os conhecimentos sobre determinado assunto. Essa característica pode explicar, também, o alto índice encontrado de adoção de estratégia multimétodo. Além disso, a diferença de aplicação de estratégias para os artigos acerca de processo decisório nos anais do EnANPAD e do EnADI reflete as características dos dois eventos, sendo o primeiro predominantemente quantitativo, e o segundo predominantemente qualitativo (DALLABONA; RODRIGUES JUNIOR; HEIN, 2011).

$\mathrm{Na}$ sequência, são discutidas as características dos estudos de cunho quantitativo, qualitativo e multimétodo. Por fim, é realizada uma análise da caracterização das publicações sobre processo decisório em ADI, considerando a relação entre autoria, metodologia e período de publicação.

4.1 Características dos estudos quantitativos

Referente às estratégias quantitativas utilizadas nos artigos, a Tabela 3 exibe o número de vezes que cada uma das treze técnicas listadas no Quadro 1 foi aplicada, incluindo-se a categoria "outros" e detalhando-as por evento. 
Tabela 3 - Estratégias quantitativas utilizadas

\begin{tabular}{|c|c|c|c|c|c|c|c|c|c|c|c|c|c|c|c|c|c|}
\hline \multirow[t]{2}{*}{$\begin{array}{c}\text { Estratégias } \\
\text { quantitativas }\end{array}$} & \multicolumn{2}{|c|}{$\begin{array}{c}1999 \\
-00\end{array}$} & \multicolumn{2}{|c|}{$\begin{array}{c}2001 \\
-02\end{array}$} & \multicolumn{2}{|c|}{$\begin{array}{c}2003 \\
-04\end{array}$} & \multicolumn{2}{|c|}{$\begin{array}{c}2005 \\
-06\end{array}$} & \multicolumn{2}{|c|}{$\begin{array}{l}2007 \\
-08\end{array}$} & \multicolumn{2}{|c|}{$\begin{array}{c}2009 \\
-10\end{array}$} & \multicolumn{2}{|c|}{$\begin{array}{c}2011 \\
-12\end{array}$} & \multicolumn{2}{|c|}{$\begin{array}{c}2013 \\
-14\end{array}$} & Total \\
\hline & $\mathrm{n}$ & $\%$ & $\mathrm{n}$ & $\%$ & $\mathrm{n}$ & $\%$ & $\mathrm{n}$ & $\%$ & $\mathrm{n}$ & $\%$ & $\mathrm{n}$ & $\%$ & $\mathrm{n}$ & $\%$ & $\mathrm{n}$ & $\%$ & $\%$ \\
\hline $\begin{array}{l}\text { Estatística } \\
\text { descritiva }\end{array}$ & 3 & 2,8 & 4 & 3,7 & 1 & 0,9 & 2 & 1,8 & 2 & 1,8 & 3 & 2,8 & 6 & 5,5 & 3 & 2,8 & 2422,0 \\
\hline EnADI & & & & & & & & & 2 & 1,8 & 2 & 1,8 & & & & & $4 \quad 3,7$ \\
\hline EnANPAD & 3 & 2,8 & 4 & 3,7 & 1 & 0,9 & 2 & 1,8 & & & 1 & 0,9 & 6 & 5,5 & 3 & 2,8 & $20 \quad 18,3$ \\
\hline $\begin{array}{c}\text { Análise fatorial } \\
\text { exploratória }\end{array}$ & 1 & 0,9 & & & 1 & 0,9 & 1 & 0,9 & 2 & 1,8 & 4 & 3,7 & 3 & 2,8 & 1 & 0,9 & $13 \quad 11,9$ \\
\hline EnADI & & & & & & & & & & & 2 & 1,8 & & & & & 21,8 \\
\hline EnANPAD & 1 & 0,9 & & & 1 & 0,9 & 1 & 0,9 & 2 & 1,8 & 2 & 1,8 & 3 & 2,8 & 1 & 0,9 & $11 \quad 10,1$ \\
\hline $\begin{array}{c}\text { Análise de } \\
\text { confiabilidade }\end{array}$ & 1 & 0,9 & & & 1 & 0,9 & & & 1 & 0,9 & 4 & 3,7 & 3 & 2,8 & & & $10 \quad 9,2$ \\
\hline EnADI & & & & & & & & & & & 2 & 1,8 & & & & & $2 \quad 1,8$ \\
\hline EnANPAD & 1 & 0,9 & & & 1 & 0,9 & & & 1 & 0,9 & 2 & 1,8 & 3 & 2,8 & & & 7,3 \\
\hline Teste $t$ & 1 & 0,9 & 1 & 0,9 & & & & & & & 3 & 2,8 & 2 & 1,8 & 2 & 1,8 & 8,3 \\
\hline EnADI & & & & & & & & & & & & & 1 & 0,9 & 1 & 0,9 & 1,8 \\
\hline EnANPAD & 1 & 0,9 & 1 & 0,9 & & & & & & & 3 & 2,8 & 1 & 0,9 & 1 & 0,9 & 6,4 \\
\hline $\begin{array}{l}\text { Análise de } \\
\text { correlação }\end{array}$ & 1 & 0,9 & 1 & 0,9 & 1 & 0,9 & & & & & 2 & 1,8 & 1 & 0,9 & 1 & 0,9 & 6,4 \\
\hline EnADI & & & & & & & & & & & 1 & 0,9 & & & & & 10,9 \\
\hline EnANPAD & 1 & 0,9 & 1 & 0,9 & 1 & 0,9 & & & & & 1 & 0,9 & 1 & 0,9 & 1 & 0,9 & 5,5 \\
\hline $\begin{array}{l}\text { Modelagem de } \\
\text { equaçóes } \\
\text { estruturais }\end{array}$ & & & & & & & 3 & 2,8 & 2 & 1,8 & 1 & 0,9 & & & 1 & 0,9 & 6,4 \\
\hline EnANPAD & & & & & & & 3 & 2,8 & 2 & 1,8 & 1 & 0,9 & & & 1 & 0,9 & 6,4 \\
\hline $\begin{array}{c}\text { Regressão } \\
\text { linear múltipla }\end{array}$ & & & 1 & 0,9 & & & & & & & 2 & 1,8 & 1 & 0,9 & 1 & 0,9 & 4,6 \\
\hline EnADI & & & & & & & & & & & 1 & 0,9 & & & & & $\begin{array}{ll}1 & 0,9 \\
\end{array}$ \\
\hline EnANPAD & & & 1 & 0,9 & & & & & & & 1 & 0,9 & 1 & 0,9 & 1 & 0,9 & 3,7 \\
\hline $\begin{array}{c}\text { Estatística } \\
\text { não paramétrica }\end{array}$ & & & & & & & 2 & 1,8 & & & 2 & 1,8 & 1 & 0,9 & & & $5 \quad 4,6$ \\
\hline EnADI & & & & & & & & & & & 2 & 1,8 & & & & & 21,8 \\
\hline EnANPAD & & & 1 & 0,9 & & & 2 & 1,8 & & & 2 & 1,8 & 1 & 0,9 & & & 4,6 \\
\hline $\begin{array}{c}\text { Técnicas de } \\
\text { pesquisa } \\
\text { operacional }\end{array}$ & & & & & & & 1 & 0,9 & 1 & 0,9 & & & & & 2 & 1,8 & 3,7 \\
\hline EnADI & & & & & & & & & 1 & 0,9 & & & & & 2 & 1,8 & 2,8 \\
\hline EnANPAD & & & & & & & 1 & 0,9 & & & & & & & & & 10,9 \\
\hline $\begin{array}{l}\text { Lógicas não } \\
\text { clássicas }\end{array}$ & & & & & & & 1 & 0,9 & 2 & 1,8 & & & 1 & 0,9 & & & $4 \quad 3,7$ \\
\hline EnADI & & & & & & & & & 1 & 0,9 & & & 1 & 0,9 & & & 21,8 \\
\hline EnANPAD & & & & & & & 1 & 0,9 & 1 & 0,9 & & & & & & & $\begin{array}{ll}2 & 1,8 \\
\end{array}$ \\
\hline ANOVA & 1 & 0,9 & & & & & & & & & 1 & 0,9 & 1 & 0,9 & & & 2,8 \\
\hline EnANPAD & 1 & 0,9 & & & & & & & & & 1 & 0,9 & 1 & 0,9 & & & $3 \quad 2,8$ \\
\hline $\begin{array}{c}\text { Regressão } \\
\text { logística }\end{array}$ & & & & & & & & & & & & & 1 & 0,9 & 1 & 0,9 & 21,8 \\
\hline EnANPAD & & & & & & & & & & & & & 1 & 0,9 & 1 & 0,9 & 21,8 \\
\hline Outros* & & & 2 & 1,8 & & & & & 1 & 0,9 & 4 & 3,7 & 2 & 1,8 & 4 & 3,7 & $13 \quad 11,9$ \\
\hline EnADI & & & & & & & & & & & 1 & 0,9 & & & 2 & 1,8 & 32,8 \\
\hline EnANPAD & & & 2 & 1,8 & & & & & 1 & 0,9 & 3 & 2,8 & 2 & 1,8 & 2 & 1,8 & $10 \quad 9,2$ \\
\hline Total & 8 & 7,3 & 10 & 9,2 & 4 & 3,7 & 10 & 9,2 & 11 & 10,1 & 28 & 25,7 & 221 & 20,2 & 16 & 14,7 & 109100,0 \\
\hline EnADI & & & & & & & & & 4 & & 11 & & 2 & & 5 & & 22 \\
\hline EnANPAD & 8 & & 10 & & 4 & & 10 & & 7 & & 17 & & 20 & & 11 & & 87 \\
\hline
\end{tabular}

*Árvore de decisão, Curva ROC, Redes neurais artificiais, Clusters, entre outras mencionadas apenas uma vez. Fonte: elaborada pelos autores. 
Os resultados indicam o fato de a estatística descritiva ser a estratégia quantitativa mais comumente utilizada $(22,0 \%)$, seguida da análise fatorial exploratória $(11,9 \%)$ e da análise de confiabilidade $(9,2 \%)$. O predomínio da estatística descritiva nos estudos da área de Administração também foi ressaltado por Dallabona, Rodrigues Junior e Hein (2011). Esta estratégia metodológica, geralmente, é utilizada em conjunto com outras estratégias, de modo que, dos 52 artigos quantitativos analisados, apenas doze utilizaram a estatística descritiva como única estratégia de análise de dados (Tabela 4).

A aplicação da análise fatorial exploratória $(11,9 \%)$ pode ser justificada por dois motivos: 1) a realização da pesquisa survey como uma das principais metodologias de pesquisa quantitativa em ADI (HOPPEN, MEIRELLES, 2005; LUNARDI, RIOS, MAÇADA, 2005; ROSSONI, HOCAYEN-DA-SILVA, 2007); e 2) a publicação de um grande número de artigos acerca da validação de instrumentos sobre SI e sobre apoio à tomada de decisão (ALVES et al., 2013). Nota-se que há um aumento, no decorrer do período analisado, do número de artigos sobre decisão na área de ADI que utilizam a análise fatorial exploratória como estratégia metodológica de análise dos dados. Tal resultado indica um aprimoramento no uso das técnicas estatísticas aplicadas neste campo, bem como a aplicação mais frequente nas últimas edições dos eventos, de modo geral, de técnicas estatísticas multivariadas, como pode ser observado na aplicação da análise de correlação $(6,4 \%)$, da modelagem de equações estruturais $(6,4 \%)$ e da regressão linear múltipla $(4,6 \%)$.

No que se refere aos estudos de validação de instrumentos de pesquisa, em um levantamento dos artigos publicados em ADI na década de 1990, Hoppen (1998) destacou a baixa qualidade dos trabalhos desenvolvidos na área, sendo um dos motivos apontados para isso a inexistência de validação dos instrumentos de pesquisa utilizados. Em consequência disso, o autor ressaltou a importância de um maior rigor científico na consecução de trabalhos na área. $\mathrm{O}$ que se percebe é que este cenário tem mudado com o passar dos anos, tendo em vista tanto a aplicação da análise fatorial exploratória, para a validade de construto (SELLTIZ; WRIGHTSMAN; COOK, 1987), quanto a aplicação da análise da confiabilidade da consistência interna do item, por meio do coeficiente Alfa de Cronbach (MALHOTRA, 2006). Nesse sentido, Alves et al. (2013), ao analisar a publicação brasileira sobre validação de instrumentos nos eventos e periódicos de Administração no país, identificaram que os procedimentos adotados para a validação dos instrumentos de pesquisa mais utilizados foram a análise fatorial exploratória e o coeficiente Alfa de Cronbach.

Corroborando a discussão realizada acerca dos resultados expostos na Tabela 2, na Tabela 3 é possível comprovar o uso de técnicas estatísticas mais arrojadas nos artigos publicados no EnANPAD, como a regressão logística ou o teste ANOVA, que só foram encontrados nos artigos de processo decisório desse evento, assim como os testes de inferência estatística, a exemplo do Teste $t(6,4 \%)$ (FIELD, 2009). Entretanto, curiosamente, quando se analisa a aplicação das técnicas de pesquisa operacional, geralmente relacionadas à otimização combinatória ou à programação linear, dos métodos multicritério e das lógicas não clássicas (lógica fuzzi, por exemplo), há um destaque para as publicações do EnADI. Considerandose que as edições do EnADI em que se publicaram artigos com essas estratégias quantitativas (2007, 2011 e 2013) foram realizadas em estados do sul do país (Santa Catarina e Rio Grande do Sul), pode haver uma relação com as instituições de origem - Universidade Federal do Rio Grande do Sul (UFRGS), Universidade Federal de Santa Maria (UFSM) e Universidade Federal de Santa Catarina (UFSC) - dos pesquisadores dessas áreas no país (VISENTINI et al., 2012). 
Como alguns dos trabalhos avaliados utilizam mais de uma estratégia de análise, na Tabela 4 é detalhada a distribuição dos artigos por número de técnicas em cada uma das edições dos eventos analisadas.

Tabela 4 - Número de estratégias quantitativas utilizadas

\begin{tabular}{|c|c|c|c|c|c|c|c|c|c|c|c|}
\hline & & \multicolumn{2}{|c|}{ Uma } & \multicolumn{2}{|c|}{ Duas } & \multicolumn{2}{|c|}{ Três } & \multicolumn{2}{|c|}{$\begin{array}{l}\text { Quatro ou } \\
\text { mais }\end{array}$} & \multicolumn{2}{|c|}{ Total } \\
\hline & & $\mathrm{N}$ & $\%$ & $\mathrm{~N}$ & $\%$ & $\mathrm{n}$ & $\%$ & $\mathrm{n}$ & $\%$ & $\mathrm{n}$ & $\%$ \\
\hline 1999-00 & EnANPAD & 1 & 33,3 & & & 1 & 33,3 & 1 & 33,3 & 3 & 100,0 \\
\hline 2001-02 & EnANPAD & 2 & 40,0 & 2 & 40,0 & & & 1 & 20,0 & 5 & 100,0 \\
\hline 2003-04 & EnANPAD & 1 & 50,0 & & & 1 & 50,0 & & & 2 & 100,0 \\
\hline $2005-06$ & EnANPAD & 4 & 57,1 & 3 & 42,9 & & & & & 7 & 100,0 \\
\hline \multirow{2}{*}{ 2007-08 } & EnANPAD & 2 & 50,0 & & & 1 & 25,0 & 1 & 25,0 & 4 & 100,0 \\
\hline & EnADI & 4 & 100,0 & & & & & & & 4 & 100,0 \\
\hline \multirow{2}{*}{$2009-10$} & EnANPAD & 2 & 33,3 & & & 2 & 33,3 & 2 & 33,3 & 6 & 100,0 \\
\hline & EnADI & & & & & & & 2 & 100,0 & 2 & 100,0 \\
\hline \multirow{2}{*}{ 2011-12 } & EnANPAD & 1 & 16,7 & 1 & 16,7 & 1 & 16,7 & 3 & 50,0 & 6 & 100,0 \\
\hline & EnADI & 2 & 100,0 & & & & & & & 2 & 100,0 \\
\hline \multirow{2}{*}{$2013-14$} & EnANPAD & 4 & 57,1 & 2 & 28,6 & 1 & 14,3 & & & 7 & 100,0 \\
\hline & EnADI & 3 & 75,0 & 1 & 25,0 & & & & & 4 & 100,0 \\
\hline Total & & $26 *$ & $\mathbf{5 0 , 0}$ & 9 & 17,3 & 7 & 13,5 & 10 & 19,2 & 52 & 100,0 \\
\hline
\end{tabular}

*doze artigos utilizaram a estatística descritiva como único método.

Fonte: elaborada pelos autores.

Há o predomínio do uso de apenas uma estratégia por artigo: dos 26 artigos com essa característica, doze são referentes à estatística descritiva. Entretanto, dentre os artigos com múltiplas estratégias, há a prevalência daqueles que utilizaram, pelo menos, quatro. É interessante perceber que, dos artigos publicados no EnADI, a maioria aplica uma ou poucas estratégias quantitativas, com exceção da edição de 2009, em que os dois artigos quantitativos sobre processo decisório publicados no evento utilizaram quatro ou mais estratégias.

4.2 Características dos estudos qualitativos e multimétodo

A utilização de estratégias qualitativas de pesquisa tem ocupado "[...] um reconhecido lugar entre as várias possibilidades de se estudar os fenômenos que envolvem os seres humanos e suas intrincadas relações sociais, estabelecidas em diversos ambientes" (GODOY, 1995, p. 21). Nesse sentido, Araújo, Gomes e Lopes (2012) desta- cam a ascensão dos trabalhos no campo da Administração que utilizam métodos qualitativos de pesquisa, tendo em vista as mudanças pelas quais as organizações vêm passando, sendo necessário não apenas entender, mas compreender de modo mais aprofundado os fenômenos sociais vivenciados. No campo dos estudos acerca do processo decisório em ADI, observa-se um aumento considerável na aplicação de estratégias qualitativas, conforme indica a Tabela 5. 
Tabela 5 - Estratégias qualitativas utilizadas

\begin{tabular}{|c|c|c|c|c|c|c|c|c|c|c|c|c|c|c|c|c|c|}
\hline & \multicolumn{2}{|c|}{$\begin{array}{l}1999 \\
-00\end{array}$} & $\begin{array}{c}2001 \\
-02\end{array}$ & \multicolumn{2}{|c|}{$\begin{array}{c}2003 \\
-04\end{array}$} & \multicolumn{2}{|c|}{$\begin{array}{l}2005 \\
-06\end{array}$} & \multicolumn{2}{|c|}{$\begin{array}{l}2007 \\
-08\end{array}$} & \multicolumn{2}{|c|}{$\begin{array}{c}2009 \\
-10\end{array}$} & \multicolumn{2}{|c|}{$\begin{array}{l}2011 \\
-12\end{array}$} & \multicolumn{2}{|c|}{$\begin{array}{l}2013 \\
-14\end{array}$} & \multicolumn{2}{|c|}{ Total } \\
\hline & $\mathrm{n}$ & $\%$ & n $\%$ & $\mathrm{n}$ & $\%$ & $\mathrm{n}$ & $\%$ & $\mathrm{n}$ & $\%$ & $\mathrm{n}$ & $\%$ & $\mathrm{n}$ & $\%$ & $\mathrm{~N}$ & $\%$ & $\mathrm{~N}$ & $\%$ \\
\hline Estudo de caso & & & & 2 & 3,0 & 3 & 4,5 & 5 & 7,5 & 4 & 6,0 & 2 & 3,0 & 3 & 4,5 & 19 & 28,4 \\
\hline EnADI & & & & & & & & 1 & 1,5 & 1 & 1,5 & 2 & 3,0 & & & 4 & 6,0 \\
\hline EnANPAD & & & & 2 & 3,0 & 3 & 4,5 & 4 & 6,0 & 3 & 4,5 & & & 32 & 4,5 & 15 & 22,4 \\
\hline Ensaio teórico & & & & & & & & 1 & 1,5 & 2 & 3,0 & 4 & 6,0 & 57 & 7,5 & 12 & 17,9 \\
\hline EnADI & & & & & & & & & & 1 & 1,5 & 3 & 4,5 & 1 & 1,5 & 5 & 7,5 \\
\hline EnANPAD & & & & & & & & 1 & 1,5 & 1 & 1,5 & 1 & 1,5 & 4 & 6,0 & 7 & 10,4 \\
\hline $\begin{array}{l}\text { Análise de } \\
\text { conteúdo }\end{array}$ & & & & & & 2 & 3,0 & 3 & 4,5 & 1 & 1,5 & 1 & 1,5 & 2 & 3,0 & 9 & 11,9 \\
\hline EnADI & & & & & & & & 1 & 1,5 & & & & & & & 1 & 1,5 \\
\hline EnANPAD & & & & & & 2 & 3,0 & 2 & 3,0 & 1 & & 1 & 1,5 & 2 & 3,0 & 8 & 10,4 \\
\hline $\begin{array}{l}\text { Entrevista em } \\
\text { profundidade }\end{array}$ & & & & & & 1 & 1,5 & 1 & 1,5 & 1 & 1,5 & & & 2 & 3,0 & 5 & 7,5 \\
\hline EnADI & & & & & & & & & & 1 & 1,5 & & & & & 1 & 1,5 \\
\hline EnANPAD & & & & & & 1 & 1,5 & 1 & 1,5 & & & & & 23 & 3,0 & 4 & 6,0 \\
\hline $\begin{array}{l}\text { Análise docu- } \\
\text { mental }\end{array}$ & & & & & & 1 & 1,5 & 1 & 1,5 & & & 1 & 1,5 & 1 & 1,5 & 4 & 6,0 \\
\hline EnADI & & & & & & & & 1 & 1,5 & & & 1 & 1,5 & 11 & 1,5 & 3 & 4,5 \\
\hline EnANPAD & & & & & & 1 & 1,5 & & & & & & & & & 1 & 1,5 \\
\hline $\begin{array}{c}\text { Análise do } \\
\text { discurso }\end{array}$ & & & & & & & & & & 2 & 3,0 & 1 & 1,5 & 1 & 1,5 & 4 & 6,0 \\
\hline EnADI & & & & & & & & & & 1 & 1,5 & & & & & 1 & 1,5 \\
\hline EnANPAD & & & & & & & & & & 1 & 1,5 & 1 & 1,5 & 11 & 1,5 & 3 & 4,5 \\
\hline Outros* & 2 & 3,0 & & & & & & 5 & 7,5 & 4 & 6,0 & 2 & 3,0 & 11 & 1,5 & 14 & 20,9 \\
\hline EnADI & & & & & & & & 3 & 4,5 & 1 & 1,5 & & & 11 & 1,5 & 5 & 7,5 \\
\hline EnANPAD & 2 & 3,0 & & & & & & 2 & 3,0 & 3 & 4,5 & 2 & 3,0 & & & 9 & 13,4 \\
\hline Total & 2 & 3,0 & & 2 & 3,0 & 7 & 10,4 & 16 & 23,9 & 14 & 20,9 & 111 & 16,4 & 152 & 22,4 & 67 & 100 \\
\hline EnADI & & & & & & & & 6 & & 5 & & 6 & & 3 & & 20 & \\
\hline EnANPAD & 2 & & & 2 & & 7 & & 10 & & 9 & & 5 & & 12 & & 47 & \\
\hline
\end{tabular}

* Pesquisa-ação, Groundedtheory, Análise de redes, Proposição de instrumento de pesquisa etc. Fonte: elaborada pelos autores.

A estratégia qualitativa mais utilizada foi o estudo de caso $(28,4 \%)$, presente em artigos publicados, principalmente, nos anais do EnANPAD, resultado que é corroborado por estudos anteriores (HOPPEN, MEIRELLES, 2005; LUNARDI, RIOS, MAÇADA, 2005; ROSSONI, HOCAYEN-DASILVA, 2007). Dentre os 16 trabalhos premiados ou que receberam menção honrosa na divisão acadêmica de ADI do EnANPAD, entre os anos de 1997 a 2004, Diniz et al. (2006) encontraram oito com abordagem qualitativa ou mista, sendo o estudo de caso o método adotado em todos eles. Entretanto, esses autores fazem uma crítica ao rigor metodológico e à consistência desses estudos:

Muitos dos artigos analisados colocam o leitor na situação de não saber como as categorias ou os temas foram definidos a partir dos dados, como as decisões chave foram tomadas no processo de pesquisa e a origem das conclusões apresentadas; em alguns casos, os achados parecem não se fundamentar nos dados (DINIZ et al., 2006, p. 11).

O ensaio teórico também desponta como importante estratégia qualitativa adotada nas investigações do 
processo decisório em ADI (17,9\%), sendo crescente a publicação deste tipo de estudo a partir do ano de 2007 no EnANPAD e da edição de 2009 do EnADI. O uso frequente dessa estratégia nos artigos da área de ADI também foi apontado por Hoppen (1998) e Rossoni e Hocayen-Da-Silva (2007). Já a análise documental não é uma estratégia muito frequente entre os artigos analisados, representando apenas $6 \%$ da amostra.
Dentre as estratégias de análise dos dados qualitativos, a análise de conteúdo predominou $(13,4 \%)$ se comparada à análise do discurso (6\%). Tal resultado pode estar relacionado à aplicação da análise de conteúdo como ferramenta de análise das entrevistas em profundidade e da própria análise documental, tendo em vista que muitas das estratégias qualitativas são utilizadas em conjunto, conforme indica a Tabela 6 .

Tabela 6 - Número de estratégias qualitativas utilizadas

\begin{tabular}{|c|c|c|c|c|c|c|c|c|c|}
\hline & & \multicolumn{2}{|c|}{ Uma } & \multicolumn{2}{|c|}{ Duas } & \multicolumn{2}{|c|}{ Três } & \multicolumn{2}{|c|}{ Total } \\
\hline & & $\mathrm{n}$ & $\%$ & $\mathrm{n}$ & $\%$ & $\mathrm{~N}$ & $\%$ & $\mathrm{~N}$ & $\%$ \\
\hline 1999-00 & EnANPAD & & & 1 & 2,3 & & & 1 & 100,0 \\
\hline 2001-02 & EnANPAD & & & & & & & & \\
\hline 2003-04 & EnANPAD & 2 & 4,5 & & & & & 2 & 100,0 \\
\hline 2005-06 & EnANPAD & 4 & 9,1 & & & 1 & 2,3 & 5 & 100,0 \\
\hline \multirow{2}{*}{ 2007-08 } & EnANPAD & & & 5 & 11,4 & & & 5 & 100,0 \\
\hline & EnADI & 3 & 6,8 & & & 1 & 2,3 & 4 & 100,0 \\
\hline \multirow{2}{*}{$2009-10$} & EnANPAD & 2 & 4,5 & 2 & 4,5 & 1 & 2,3 & 5 & 100,0 \\
\hline & EnADI & 3 & 6,8 & 1 & 2,3 & & & 4 & 100,0 \\
\hline \multirow{2}{*}{$2011-12$} & EnANPAD & 1 & 2,3 & 2 & 4,5 & & & 3 & 100,0 \\
\hline & EnADI & 4 & 9,1 & 1 & 2,3 & & & 5 & 100,0 \\
\hline \multirow{2}{*}{ 2013-14 } & EnANPAD & 4 & 9,1 & 4 & 9,1 & & & 8 & 100,0 \\
\hline & EnADI & 1 & 2,3 & 1 & 2,3 & & & 2 & 100,0 \\
\hline Total & & 24 & 54,5 & 17 & 38,6 & 3 & 6,8 & 44 & 100,0 \\
\hline
\end{tabular}

Fonte: elaborada pelos autores.

Dos 44 artigos qualitativos analisados, 54,5\% utilizaram apenas uma estratégia metodológica, e 38,6\% aplicaram duas estratégias. Dentre estes, a segunda técnica é, na maioria dos casos, a análise de conteúdo (13,6\%). Uma das vantagens da combinação de estratégias qualitativas é a busca da validade interna desse tipo de pesquisa. Flick (2009) defende que a combinação de estratégias qualitativas tem sido amplamente aceita, tanto na coleta quanto na análise de dados, eliminando, muitas vezes, a limitação gerada pelo emprego de uma única abordagem.

O uso de estratégia multimétodo também considera a utilização conjunta das pesquisas qualitativas e quantitativas. Neste trabalho, buscou-se identificar as estratégias mais utilizadas na triangulação dos dados quantitativos e qualitativos, conforme apresentado na Tabela 7. Optou-se por realizar essa discussão, tendo em vista que muitas das ponderações acadêmicas em Administração ainda refletem pesquisas fragmentadas, bem como modelos e abordagens mutuamente excludentes (BENEDICTO et al., 2012). Assim, buscou-se compreender se e de que forma os artigos sobre processo decisório em ADI utilizam a triangulação metodológica e superam essas questões controversas postas na literatura. 
Tabela 7 - Estratégias multimétodo utilizadas

\begin{tabular}{l|cccc}
\hline \multicolumn{1}{c|}{ Métodos } & $\begin{array}{c}\text { Estudo de } \\
\text { caso }\end{array}$ & $\begin{array}{c}\text { Entrevista } \\
\text { em profundi- } \\
\text { dade }\end{array}$ & $\begin{array}{c}\text { Análise do- } \\
\text { cumental }\end{array}$ & Outros \\
\hline Estatística descritiva & $21,4 \% *$ & $7,1 \%$ & & $14,3 \%$ \\
Análise fatorial exploratória & $3,6 \%$ & & & \\
Análise de confiabilidade & $3,6 \%$ & & \\
Teste $\boldsymbol{t}$ & $3,6 \%$ & & \multirow{2}{*}{$7,1 \%$} & \\
Regressão linear & $3,6 \%$ & & \\
Estatística não paramétrica & $7,1 \%$ & & \\
Técnicas de pesquisa operacional & $39,3 \%$ & $39,3 \%$ & \\
Lógicas não clássicas & $3,6 \%$ & $3,6 \%$ & \\
Regressão logística & $3,6 \%$ & & \\
Outros & $21,4 \%$ & $7,1 \%$ & & \\
\hline
\end{tabular}

*Percentual calculado sobre o total (28) de artigos multimétodo.

Fonte: elaborada pelos autores.

Observou-se que, dentre os artigos com múltiplos métodos, há a predominância da aplicação do estudo de caso com a estatística descritiva $(21,4 \%)$ ou com as técnicas de pesquisa operacional $(39,3 \%)$. No segundo caso, como neste artigo os métodos multicritério de decisão foram considerados como técnicas de pesquisa operacional, as inúmeras publicações utilizando metodologia multicritério para apoio à decisão construtivista (MCDA-C) são as responsáveis por essa alta proporção. A integração de estratégia qualitativa e quantitativa na abordagem dessa metodologia vai ao encontro da sua operacionalização (ENSSLIN et al., 2008, p. 145), que é "realizada por meio de três fases básicas, diferenciadas, mas intrinsecamente correlacionadas: i. a estruturação do contexto decisório; ii. a construção de um modelo de avaliação de alternativas/ações; e iii. a formulação de recomendações para os cursos de ações mais satisfatórias". Devido às características dessas etapas nos artigos avaliados que utilizaram a MCDA-C, estes também aplicaram a entrevista em profundidade como estratégia de pesquisa.

4.3 Caracterização das publicações sobre processo decisório em ADI

Com a finalidade de demonstrar como estão caracterizadas as publicações sobre processo decisório em ADI, analisou-se a autoria dos trabalhos publicados no EnANPAD (1999-2014) e no EnADI (2007, 2009, 2011 e 2013), considerando a relação entre o número de autores em cada artigo e o evento científico em que foram publicados. Na Figura 1, exposta a seguir, é apresentada essa relação.

Figura 1 - Relação entre número de artigos publicados e número de autores por artigo

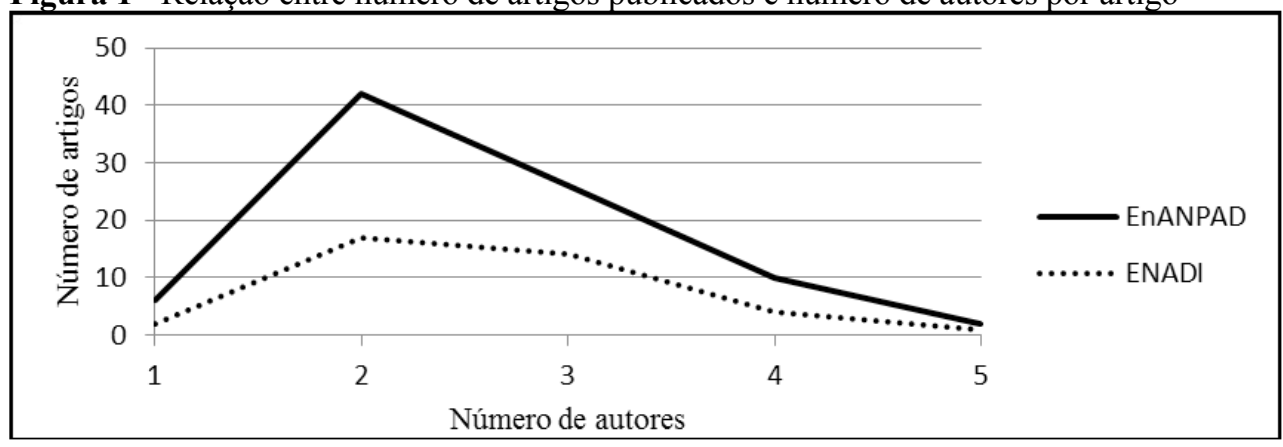

Fonte: elaborada pelos autores. 
Conforme a Figura 1, percebe-se a predominância de artigos com dois autores em ambos os eventos, resultando em uma média de 2,53 autores por artigo no EnANPAD e 2,61 autores por artigo no EnADI. Dos artigos publicados no EnANPAD, 48,4\% e 30,23\% foram escritos por dois e três autores, respectivamente. Quando se analisa a produção do EnADI, encontra-se resultado semelhante: $44,74 \%$ dos artigos pertencem dois autores, e $36,84 \%$ pertencem a três autores. Esses resultados vão ao encontro do apresentado por Espartel et al. (2013), que identificaram uma média de 2,62 autores por trabalho nos artigos publicados em ADI no EnANPAD, para o período de 2000 a 2010. Entretanto, esses estudiosos apontam que $13,6 \%$ das publicações em ADI foram realizadas por apenas um autor no período de análise, enquanto que, neste trabalho, considerando exclusivamente os artigos sobre processo decisório em ADI, a proporção foi de apenas 6,5\%. Espartel et al. (2013, p. 90) destacam a vantagem da publicação em coautoria, afirmando que "por meio da colaboração científica, a academia brasileira de Administração pode almejar novos patamares na academia mundial e a qualificação da pesquisa (não somente o incremento quantitativo)".

A discussão acerca de coautoria nos artigos sobre processo decisório em ADI pode ser ampliada por meio da análise da evolução dos vínculos de publicação ao longo dos anos. Na Figura 2, apresenta-se tal evolução, com base na relação entre o número de autores por artigo e o período em que foram publicados.

Figura 2- Relação entre número de autores por artigo e período de publicação

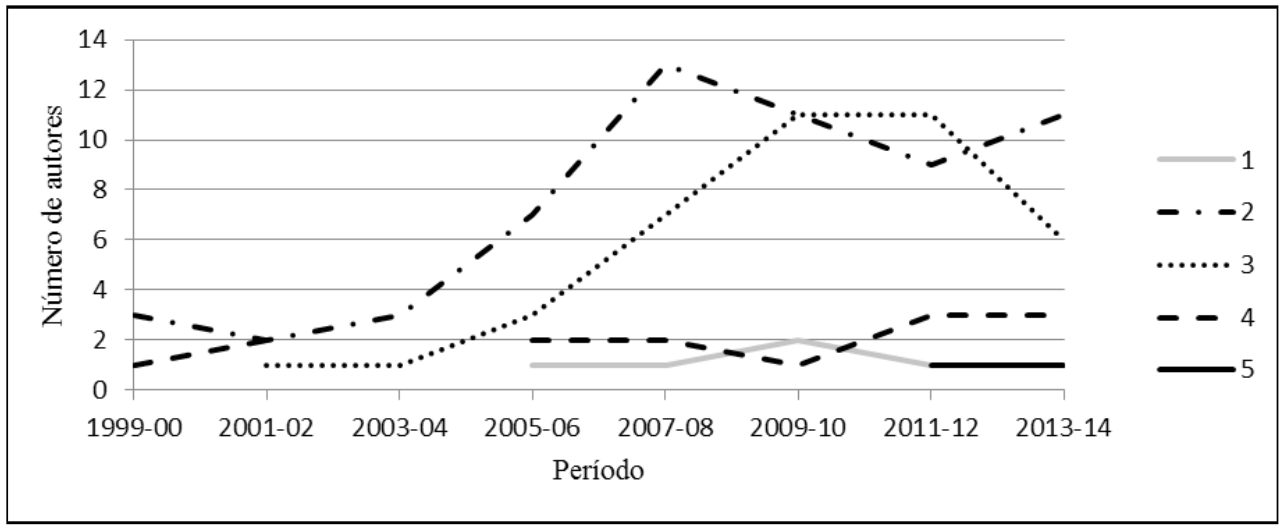

Fonte: elaborada pelos autores.

Assim como destacado por Espartel et al. (2013) ao tratar dos estudos em Administração, há um incremento nas pesquisas sobre processo decisório publicadas em coautoria na última década. A Figura 2 ilustra que apenas a partir de 2005 são verificados artigos com cinco autores e que são mais amplamente desenvolvidos trabalhos com quatro autores. Tratando-se especificamente dos levantamentos realizados em ADI, este resultado também é corroborado. Lunardi, Rios e Maçada (2005), avaliando as publicações da área entre
1997 e 2000 , indicam que $42,86 \%$ e $19,55 \%$ dos artigos foram escritos por dois e por três autores, respectivamente, proporção que no período entre 2001 e 2004 subiu para $57,21 \%$ e $23,38 \%$. Resultados semelhantes foram encontrados por Rossoni e Hocayen-da-Silva (2007), que verificaram que cerca de $57 \%$ do total de artigos publicados em ADI no EnANPAD, entre 2001 e 2006, são da autoria de dois pesquisadores. Avaliando a evolução das publicações, eles detectaram que, no período entre 2001 e $2003,58 \%$ e $16 \%$ dos artigos 
tiveram dois e três autores, respectivamente, e que, entre 2004 e 2006 , essa proporção passou a ser de $56 \%$ e $24 \%$. Esses autores também identificaram que, no primeiro período de avaliação, houve apenas um artigo com cinco autores, enquanto que no segundo período foram publicados cinco artigos com cinco autores. Esses resultados indicam que as pesquisas sobre processo decisório seguem as características dos estudos da área de ADI.
A última análise realizada recai sobre a relação entre a estratégia metodológica adotada nos artigos e o número de autores. Essa análise é interessante, tendo em vista que Espartel et al. (2013) identificaram, ao realizar ampla análise da produção científica em Administração, que os estudos de cunho quantitativo tendem, mais do que os qualitativos, a ser realizados em coautoria. Assim, buscou-se investigar se este fenômeno também é visualizado nos estudos acerca do processo decisório, conforme demonstra a Figura 3.

Figura 3- Relação entre número de artigos publicados por estratégia metodológica e número de autores por artigo

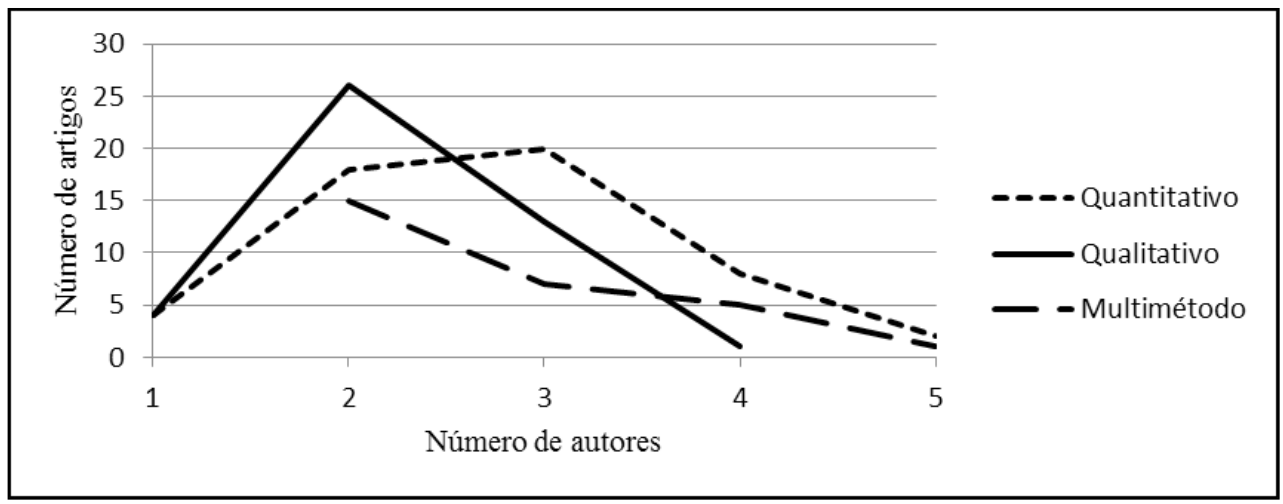

Fonte: elaborada pelos autores.

Os achados de Espartel et al. (2013), de que a estratégia metodológica utilizada pelos estudos em Administração requer quantidades diferentes de pesquisadores, também foram comprovados neste trabalho. Os dados apresentados na Figura 3 indicam que os trabalhos quantitativos (média $=2,73)$ e multimétodo (média $=2,71)$ apresentam uma média de autores superior àquela encontrada nos artigos qualitativos (média $=2,25$ ). A maioria dos artigos de estratégia quantitativa $(38,46 \%)$ foi escrita por três autores, e apenas $7,69 \%$ desses artigos tiveram um único autor. Já os estudos qualitativos tiveram predomínio de dois autores $(59,09 \%)$, sendo apenas 9,09\% elaborados por um único pesquisador. Dos trabalhos com estratégia multimé- todo, nenhum possui apenas um autor, sendo a maioria $(53,57 \%)$ elaborada por dois autores. Outro aspecto a destacar é que, dentre os artigos selecionados, nenhum de estratégia qualitativa teve mais do que quatro autores.

Rossoni e Hocayen-da-Silva (2007) observaram que, na área de ADI, há a tendência de um maior número de autores que trabalham em conjunto em comparação a outras áreas da Administração. Segundo esses pensadores, essa é uma característica positiva, "pois a produção de artigos científicos em conjunto com outros pesquisadores da área de administração pode contribuir para a troca de experiência e para uma elevação na qualidade dos trabalhos" (2007, p. 10). 


\section{Considerações finais}

Objetivou-se, neste estudo, analisar comparativa e evolucionariamente a produção científica nacional sobre processo decisório em SI, por meio de dados levantados a partir dos artigos publicados nos anais do EnANPAD e do EnADI, entre 1999 e 2014. Para atingir tal objetivo, investigaram-se 124 trabalhos, discutindo-se a relação entre autoria, estratégia metodológica e período de publicação.

Ao analisar as estratégias metodológicas adotadas pelos trabalhos publicados no EnANPAD, percebe-se predominância de estudos que optaram pela utilização de algum método quantitativo como ferramenta de pesquisa para análise, validação ou outra finalidade específica. No EnADI, por sua vez, há a prevalência de artigos que adotaram estratégias qualitativas e multimétodo como ferramenta de pesquisa.

Quanto às estratégias quantitativas, constatou-se a predominância de uso de uma única estratégia por artigo publicado, sendo a estatística descritiva, a análise fatorial exploratória e a análise de confiabilidade as estratégias mais presentes em ambos os eventos da ANPAD analisados. Com o decorrer do tempo, observa-se aumento na utilização da análise fatorial exploratória e de outros métodos quantitativos, o que pode indicar evolução científica da área, conforme argumentam Palmer, Sesé e Montaño (2005), já que o uso da estatística em qualquer área científica pode ser considerado um elemento-chave na avaliação do seu grau de desenvolvimento.

No que concerne às estratégias qualitativas, constatou-se a predominância de uma única estratégia metodológica, sendo o estudo de caso a estratégia mais presente nos eventos analisados. Observando-se separadamente cada evento, percebe-se, no EnADI, a priorização de ensaios teóricos. Considerando-se o despontar crescente de ensaios teóricos a partir de 2007 e o fato de que o EnADI ocorre bianualmente, conjec- tura-se que o estudo de caso poderá ser no futuro a estratégia mais utilizada nas pesquisas qualitativas de processo decisório em ADI. Nos estudos multimétodo, observou-se, em grande parte, a utilização conjunta do estudo de caso aliado à estatística descritiva ou a técnicas de pesquisa operacional.

Ao proceder à caracterização das publicações sobre processo decisório em ADI, constatou-se primeiramente a predominância de artigos com dois e três autores em ambos os eventos. Tal resultado indica que os pesquisadores, possivelmente, percebem a importância do estabelecimento de parcerias acadêmicas para a evolução do seu campo de estudo. Além disso, ocorreu crescimento acentuado, a partir do ano de 2005, de artigos com coautoria, o que pode, também, corroborar tal indicativo. Por fim, os achados demonstram que são poucos os estudos que adotaram estratégias qualitativa ou quantitativa realizados por um único autor e que nenhum estudo multimétodo foi realizado de forma individual. Por outro lado, pode-se pressupor que os esforços de coleta, análise, modelagem e outros procedimentos necessários, inerentes à consecução de tais estudos, sejam de difícil execução individual.

Para pesquisas futuras, sugerese que sejam avaliados também outros eventos da área de Administração, como os Seminários em Administração (SEMEAD-USP) e a Conferência Internacional sobre Sistemas de Informação e Gestão de Tecnologia (CONTECSI), a fim de identificar a evolução dos estudos acerca de processo decisório nas áreas de tecnologia da informação e SI. Além disso, é importante ampliar os critérios aqui avaliados, verificando a qualidade dos artigos de natureza quantitativa, qualitativa e multimétodo, bem como seu correto enquadramento metodológico, conforme sugerido por Hoppen (1998) e Hoppen e Meirelles (2005). Ainda, é interessante e relevante que se investigue a rede de relações entre os pesquisadores, as instituições e os 
métodos utilizados, com a identificação dos pesquisadores mais profícuos e de sua inserção internacional, fomentando novas conclusões sobre a natureza da utilização dos estudos qualitativos e quantitativos sobre o processo decisório em SI, o que pode contribuir para a construção da identidade da temática na área de ADI.

\section{Referências}

1. ABE, J. M. et al. Lógica Paraconsistente Anotada Evidencial Et. Santos: Editora Comunicar, 2011.

2. ALVES, J. N. et al. Os Caminhos da Produção Brasileira sobre o Processo de Validação de Instrumentos de Pesquisa em Administração. In: IV ENCONTRO DE ENSINO E PESQUISA EM ADMINISTRAÇÃO E CONTABILIDADE EnEPQ, 2013, Brasília. Anais... Brasília: EnEPQ, 2013.

3. ARAÚJO, R. M.; GOMES, F. P.; LOPES, A. O. B. Pesquisa em Administração: qualitativa ou quantitativa?. Revista Vianna Sapiens, Juiz de Fora, v. 3, p. 151-175, 2012.

4. BARDIN, L. Análise de conteúdo. Lisboa: Edições, 1977.

5. BECKER, J. L. et al. Informação e decisão: Sistemas de apoio e seu impacto. Porto Alegre: Ortiz, v. 74, 1997.

6. BENEDICTO, G. C.; STIEG, C. M.; ANDRADE, G. H. N. Contribuições da História da Ciência ao Debate sobre Metodologia Qualitativa e Quantitativa nos Estudos Organizacionais e Administrativos. Revista de administração da Unimep, Piracicaba, v. 10, p. 179202, 2012.

7. BERTERO, C O.; CALDAS, M. P.; WOOD JÚNIOR, T. Produção científica em administração de empresas: provocações, insinuações e contribuições para um Debate Local. In: ENCONTRO ANUAL DA ANPAD, 1998,
Anais... Foz do Iguaçu: ANPAD, 1998.

8. BERTERO, C. O.; CALDAS, M. P.; WOOD JÚNIOR, T. Produção científica em administração de empresas: provocações, insinuações e contribuições para um Debate Local, RAC - Revista de Administração Contemporânea, Curitiba, v. 3, n. 1, p. 147-178, jan./abr. 1999.

9. CASSARRO, A. C. Sistemas de Informações para tomadas de decisões. 3 ed, São Paulo: Pioneira Thomson Learning, 1998.

10. CAUTELA, A. L.; POLLONI, E. G. F. Sistemas de Informação na administração de empresas. 4. ed. São Paulo: Atlas, 1991.

11. CERVO, A. L.; BERVIAN, P. A. Metodologia científica. 5. ed. São Paulo: Prentice hall, 2002.

12. CHILD, J. O. H. N.; ELBANNA, S. A. I. D.; RODRIGUES, S. The political aspects of strategic decision making. The handbook of decision making, p. 105-137, 2010.

13. CIRANI, C. B. S.; SILVA, H. H. M.; CAMPANARIO, M. A. A evolução do ensino da pós-graduação estrito senso em Administração no Brasil. Revista de Administração Contemporânea, Rio de Janeiro, v. 16, n. 6, p. 765-783, 2012.

14. COHEN, M. D.; MARCH, J. C.; OLSEN, J. P. A garbage can model of organizational choice. Administrative Science Quarterly, v. 17, n. 1, p. 1-25, 1972.

15. CORTINA, J. M. What is coefficient alpha? An examination of theory and applications. Journal of Applied Psychology, [S.1.] v. 78, p. 98-104. 1993

16. DALLABONA, L. F.; RODRIGUES JUNIOR, M. M.; HEIN, N. Métodos Estatísticos: Análise dos Estudos Publicados nos Anais de Congressos da ANPAD. In: XIV SEMEAD, 2011. Anais... São Paulo: SEMEAD, 2011. 
17. DINIZ; E. H. et al. Abordagens Epistemológicas em Pesquisas Qualitativas: além do positivismo nas pesquisas na área de Sistemas de Informação. In: XXX EnANPAD, 2006. Anais... Salvador: ANPAD, 2006.

18. ENSSLIN, S. R. et al. Uma metodologia multicritério (MCDA-C) para apoiar o gerenciamento do capital intelectual organizacional. RAM - Revista de Administração Mackenzie (Online), v. 9, p. 136-162, 2008.

19. ESPARTEL, L. B. et al. Colaboração científica em administração: análise das publicações em coautoria no Brasil no período 2000-201 0. RGO - Revista Gestão Organizacional (Online), v. 6, p. 77 - 92, 2013.

20. FIELD, A. Descobrindo a ESTATÍSTICA usando o SPSS. 2. ed., Porto Alegre: Artmed. 2009.

21. FLEURY, S. (Coord.) Análise do perfil dos artigos publicados na revista de administração pública - RAP no Período 1992-2002. Rio de Janeiro: EAESP/FGV, 2003.

22. FLICK, U. Introdução à pesquisa qualitativa. 3. ed. São Paulo: Artmed, 2009.

23. FREITAS, H. M. R.; BECKER, J. L.; MARCOLIN, C. B. Uma Visão sobre a Pesquisa Acadêmica em SI no Brasil: 1994 a 2013. In: XXXVIII EnANPAD 2014. Anais... Rio de Janeiro: ANPAD, 2014.

24. GIBCUS, P.; VERMEULEN, P. AM; RADULOVA, E. The decision-making entrepreneur: A literature review. Entrepreneurial strategic decision-making: A cognitive perspective, p. 11-40, 2008.

25. GIBSON, D. R. Turn-taking and Geopolitics in the Making of Decisions. Research in the Sociology of Organizations, v. 36, p. 19-30, 2012.

26. GODOY, A. S. Introdução à pesquisa qualitativa e suas possibilidades. Revista de Administração de Empresas, Rio de Janeiro, v. 35, n. 2, p. 57-63, mar./abr., 1995.
27. GOLDBARG, M.. C.; LUNA, H. P. L. Otimização combinatória e programação linear: modelos e algoritmos. Rio de Janeiro: Elsevier, 2005

28. HAIR Jr., J. F. et al. Fundamentos de Métodos de pesquisa em administração. Porto Alegre: Bookman, 2005b.

29. HAIR Jr., J. F. et al. Análise Multivariada de Dados. Porto Alegre: Bookman, 2005a.

30. HÉKIS, H. R. et al. Sistema de informação: benefícios auferidos com a implantação de um sistema WMS em um centro de distribuição do setor têxtil em NATAL/ RN. Revista de Administração e Inovação, v. 10, n. 4, out./dec., 2013, pp. 85-109.

31. HOPPEN, N. Sistemas de Informação no Brasil: uma análise dos artigos científicos dos anos 90. Revista Contemporânea de Administração, Curitiba, v. 2, n. 3, 1998.

32. HOPPEN, N.; MEIRELLES, F. S. Sistemas de Informação: Um Panorama de Pesquisa Científica entre 1990 e 2003. Revista de Administração de Empresas, São Paulo, v.45, n.1, 2005.

33. KLEM, L. Structural equation modeling. In: GRIMM, L.G.; YARNOLD, P. R (Eds.). Reading and understanding more multivariate statistics. Washington: American Psychological Association, 2006.

34. LATIF, S. A. A análise fatorial auxiliando a resolução de um problema real de pesquisa de marketing. Caderno de Pesquisas em Administração, São Paulo, V.0, n.0, p. 1-10, 1994.

35. LAUDON, Kenneth C.; LAUDON, Jane. Price. Sistemas de informação gerenciais: administrando a empresa digital. 5. ed. São Paulo: Prentice Hall, 2004.

36. LÖBLER, M. L. VISENTINI, M. S.; FERREIRA, A. C. Transversalidade entre Cognição e Sistemas de Informação: um mapeamento dos principais periódicos internacionais. Organizações \& Sociedade, Salvador, v.18, n.56, p. 153-173, 2011. 
37. LÖBLER, M. L. Processamento da informação: uma avaliação dos diferentes níveis de conhecimento no processo de decisão. 215p. Tese (doutorado em Administração) Universidade Federal do Rio Grande do Sul. Porto Alegre, 2005.

38. LUNARDI, G. L.; RIOS L. R.; MAÇADA, A. C. F. Pesquisa em Sistemas de Informação: uma análise a partir dos artigos publicados no EnANPAD e nas principais revistas nacionais de Administração. In: XXVIII ENCONTRO DA ANPAD, 2005. Anais... Brasília: ANPAD, 2005.

39. MACHADO-DA-SILVA, C. L.; CUNHA, V. C.; AMBONI, N. Organizações: o estado da arte da produção acadêmica no Brasil. In: XIV ENCONTRO ANUAL DA ANPAD, 1990. Anais... Florianópolis: ANPAD, 1990.

40. MAlhotra, N. K. Pesquisa de Marketing: Uma Orientação Aplicada. 3. ed. Porto Alegre: Bookman, 2006.

41. MATTOS, P. L. C. L. Análise de entrevistas não estruturadas: da formalização à pragmática da linguagem. In: SILVA, A. B.; GODOI, C. K.; BANDEIRA-DE-MELO, R. (orgs). Pesquisa qualitativa em estudos organizacionais: paradigmas, estratégias e métodos. São Paulo: Saraiva, 2010.

42. MAZZON, J. A.; HERNANDEZ, J. M. C. Produção científica brasileira em marketing no período 2000-2009. Revista de Administração de Empresas, São Paulo, v.53, n.1, p. 67-80, 2013.

43. MOREIRA, S. V. Análise documental como método e como técnica. In: DUARTE, J.; BARROS, A. (Org.). Métodos e técnicas de pesquisa em comunicação. São Paulo: Atlas, 2005. p. 269-279

44. MORGAN, G.; SMIRCICH, L. The Case of Qualitative Research. Academy of Management Review, [S.1.], v. 5, p. 491-500, 1980.

45. O'BRIEN, J. A. Sistemas de informação: $\mathrm{e}$ as decisões gerenciais na era da Internet. 2. ed. São Paulo: Saraiva 2004.
46. OLIVEIRA, M. M. de. Como fazer pesquisa qualitativa. Petrópolis: Vozes, 2007

47. ORLANDI, E. P. Análise de discurso: princípios e procedimentos. São Paulo: Pontes, 1999.

48. OSCA-LLUCH, J. Aplicación Del análisis de redes al estudio de La investigación española de historia de laciencia. REDES-Revista hispana para el análisis de redes sociales, Espanha, v. 19, n. 6, p. 122-143, 2010.

49. PALMER, A. L.; SESÉ, A.; MONTAÑO, J. J. Tourism and Statistics Bibliometric Study 1998- 2002. Annals of Tourism Research, [S.1.] v. 23, n. 2, p. 167-178, 2005.

50. PAULA, G. A. Modelos de regressão com apoio computacional. São Paulo: IME-USP, 2004.

51. POLLONI, E. G. F. Administrando sistemas de informação. São Paulo, SP: Futura, 2000.

52. RAMOS, S. C.; TAKAHASHI, A. R. W.; ROGLIO, K. D. Análise da Produção Nacional sobre Processo Decisório no Período de 2004-2014. Contextus Revista Contemporânea de Economia e Gestão, v. 13, n. 3, p. 156-184, 2015.

53. RICHARDSON, R. J. Pesquisa Social, Métodos e Técnicas. 3. ed. São Paulo: Atlas, 2007.

54. ROSSONI, L.; HOCAYEN-DA-SILVA, A. J. Administração da Informação: A Produção Científica Brasileira entre 2001 e 2006. I ENCONTRO DA ADMINISTRAÇÃO DA INFORMAÇÃO, 2007. Anais... Florianópolis: EnADI, 2007.

55. SELLTIZ, C.; WRIGHTSMAN, L. $\mathrm{S}$.; $\mathrm{COOK}, \mathrm{S}$. Métodos de pesquisas nas relações sociais. 4. ed. São Paulo: Editora Pedagógica e Universitária, 1987.

56. SESÉ, A.; PALMER, A. The Current Use of Statistics in Clinical and Health Psychology Under Review. Clínica y Salud, Madrid, v. 23, n. 1, pp. 97-108, 2012. 
57. SIMON, H. A. Administrative behavior: a study of decision-making processes in administrative organization. 1. ed. New York: Macmillan Co., 1945.

58. SIQUEIRA, M. O tema recursos humanos nas reuniões da ANPAD: trajetórias e perspectivas. In: ENCONTRO ANUAL DA ANPAD, 1988. Anais... Foz do Iguaçu: ANPAD, 1988.

59. SIQUEIRA, M. C. Gestão Estratégica da Informação. Rio de Janeiro: Brasport, 2005.

60. TVERSKY, A; KAHNEMAN, D. Availability: a heuristic for judging frequency and probability. Cognitive psychology, v. 5, n. 2, p. 207-232, 1973.

61. Judgment under uncertainty: heuristics and biases. Science, $v$. 185, n. 4157, p. 1124-1131, 1974.

62. VISENTINI, M. S. et al. Sistemas De Informação Utilizando Técnicas De Pesquisa Operacional (2000-2010). Revista Alcance (online), v. 19, n. 03, p. 327-344, 2012.

63. WEBSTER, A. L. Estatística Aplicada à Administração e Economia. São Paulo: McGraw-Hill, 2006.

64. WOOD JÚNIOR, T.; PAULA, A. P. de. Pop-management: pesquisa sobre as revistas populares de gestão no Brasil. In: ENCONTRO ANUAL DA ANPAD, 2002. Anais... Salvador: ANPAD, 2002.

65. YIN, R.. K. Estudo de caso: planejamento e métodos. 3. ed. Porto Alegre: Bookman, 2005. 